\title{
Periodontal treatment outcomes in smokers: A narrative review
}

\author{
Mehmet Kanmaz', Burcu Kanmaz' ${ }^{2}$ Nurcan Buduneli ${ }^{3}$
}

\begin{abstract}
Smoking is considered as the major environmental risk factor for periodontal diseases. Smokers have a higher risk for severe periodontitis with more periodontal tissue destruction, more gingival recession, and more susceptibility for tooth loss. The aim of this narrative review is to provide up-to-date evidence on the clinical outcomes of periodontal treatment in smokers. Electronic databases were searched for studies that compare the clinical outcomes in smokers and nonsmokers following non-surgical and surgical periodontal treatment modalities and also during the supportive periodontal treatment. Clinical studies published before May 2021 were included in the review. Smokers have a higher risk for recurrence of periodontal disease and the response to non-surgical as well as surgical periodontal treatment is not as good as that of non-smokers. Moreover, there is a dose-response effect in the adverse effects of smoking on periodontal health. Compared to non-smokers, smoker patients with periodontitis tend to respond less favorably to non-surgical and surgical periodontal treatment, and exhibit recurrence more frequently during supportive periodontal treatment. Along with the periodontal treatment, smokers may be encouraged to quit. Long follow-up and the communication between the dentist and the patient give a great opportunity for such counseling.
\end{abstract}

\author{
AFFILIATION \\ 1 Department of \\ Periodontology, Faculty of \\ Dentistry, Izmir Tınaztepe \\ University, Izmir, Turkey \\ 2 Department of \\ Periodontology, Faculty of \\ Dentistry, Izmir University of \\ Democracy, Izmir, Turkey \\ 3 Department of \\ Periodontology, Faculty of \\ Dentistry, Ege University, \\ Izmir, Turkey \\ CORRESPONDENCE TO \\ Nurcan Buduneli. Department \\ of Periodontology, Faculty \\ of Dentistry, Ege University, \\ 35100 Bornova, Izmir, Turkey. \\ E-mail: nurcan.buduneli@ \\ ege.edu.tr \\ ORCID ID: https://orcid. \\ org/0000-0002-1590-5801 \\ KEYWORDS \\ periodontal diseases, \\ periodontal treatment, root \\ planning, smoking, tobacco \\ Received: 30 May 2021 \\ Revised: 19 July 2021 \\ Accepted: 9 September 2021
}

\section{INTRODUCTION}

Periodontal diseases are a group of chronic inflammatory diseases that are caused by bacteria populated on the teeth surfaces. Periodontal treatment has three phases: non-surgical, surgical, and supportive periodontal treatment. Non-surgical and supportive periodontal treatment phases are mandatory in every patient with any type and severity of periodontal disease. Surgical periodontal treatment may contain regenerative or resective goals in cases where non-surgical periodontal treatment is not sufficient to provide optimal clinical outcomes.
Basic clinical periodontal parameters for periodontal diagnosis as well as evaluation of prognosis and treatment outcomes are probing depth and clinical attachment level, gingival inflammation, and level of oral hygiene. Endpoints of active periodontal treatment have been recently revisited during the World Workshop for Classification of Periodontal and Peri-implant Diseases ${ }^{1}$. It was found that periodontitis patients with a low proportion of deep residual pockets after active periodontal therapy are more likely to be stable in long follow-up periods.

Treatment plan of a single periodontal disease case 
depends on the diagnosis of the disease, evaluation of the prognosis, and patient's expectations from the treatment. Patient-clinician cooperation plays a critical role in the eventual success of periodontal treatment. Systemic health state and presence or absence of environmental factors and psychological stress are also important factors. Smoking is accepted as the major environmental risk factor for periodontal diseases. This fact is now reflected in the current classification of periodontal diseases and the grade of periodontitis is directly modified by the smoking status and the number of cigarettes smoked per day ${ }^{2}$. Smokers have a higher risk for both the onset and progression of periodontal disease ${ }^{3,4}$. Accordingly, passive smokers exhibit probing depth and clinical attachment level values smaller than those of active smokers and greater than those of non-smokers, with significant correlations between these clinical measurements and the salivary cotinine concentrations ${ }^{5}$. Wound healing following periodontal treatment is adversely affected by smoking and smokers tend to respond less favorably to non-surgical as well as surgical periodontal treatment compared to non-smokers ${ }^{6,7}$. However, there are also studies documenting comparable clinical treatment outcomes in nonsmokers and smokers ${ }^{8-10}$. Nicotine is one of the major detrimental components of tobacco and it is regarded as the major addictive chemical of tobacco products. In vitro studies have reported detrimental effects of nicotine on various cells, possibly explaining the negative clinical outcomes together with vascular harms of tobacco products ${ }^{11}$.

The aim of this narrative review is to provide upto-date evidence on the nature of the relationship between smoking and treatment outcomes in patients with periodontal disease. Studies evaluating clinical periodontal findings following non-surgical, surgical, and supportive phases of periodontal treatment were within the scope of this review.

\section{DEVELOPMENTS}

A manual and an electronic search were performed for studies published before May 2021. Clinical intervention and follow-up studies having at least the two study groups of smoker periodontitis patients and non-smoker periodontitis patients were included in the review. The focused intervention was non-surgical or surgical periodontal treatment. Studies evaluating treatment outcomes in supportive periodontal treatment phase were also included. Electronic databases, MEDLINE (PubMed), EMBASE, Scopus were searched using specific key words. Manual search was performed in the Journal of Clinical Periodontology, Journal of Periodontology, Journal of Periodontal Research, and Journal of Dental Research.

\section{Smoking and non-surgical periodontal treatment}

Smokers usually respond less favorably to non-surgical periodontal treatment compared to non-smokers. Numerous clinical follow-up studies reported that smoker patients exhibited less reduction in probing depth and less gains in clinical attachment level values following scaling and root planing ${ }^{12-14}$. On the other hand, similar clinical outcomes in non-smokers and smokers were reported in some other studies following non-surgical periodontal treatment ${ }^{10,15}$. Accordingly, D'Aiuto et al. ${ }^{8}$ concluded that local periodontal disease-related factors such as the number of affected posterior teeth, number of interproximal periodontitis lesions, severity of baseline mobility, and deep baseline probing depths were significantly related to the clinical outcomes, whereas there was no significant relation to the smoking status. The conflicting findings published in the literature may be explained by the methodological differences between studies. Some studies report only the mean values of full-mouth probing depth and clinical attachment level measurements; the duration of follow-up after completion of the non-surgical periodontal treatment varies between studies from 1 to 12 months, and power calculations are not provided in all relevant studies $^{5,6,11-18}$.

In a recent study, Stage III and IV periodontitis patients (generalized aggressive periodontitis) either in the current smoker or never smoker group received non-surgical periodontal treatment and were followed up for six months ${ }^{16}$. The study comprised microbiological and biochemical investigations together with clinical periodontal evaluations. It was reported the clinical responses of non-smoker and smoker patients to the non-surgical periodontal treatment were comparable. However, Gramnegative bacteria repopulated much faster in the smoker patients, possibly suggesting a higher risk for recurrence. 
A recent randomized controlled clinical trial compared current smokers and never smokers with the diagnosis of chronic periodontitis in terms of their response to scaling and root planning, with and without adjunctive photodynamic therapy ${ }^{17}$. The researchers reported that clinical outcomes of nonsurgical periodontal treatment were compromised in the current smokers regardless of the content of the treatment, while never smokers' response to mechanical periodontal treatment, with and without photodynamic therapy, was similar. Another study comparing cigarette smokers, never smokers, and those individuals vaping electronic-cigarettes reported that the worst gingival inflammation was detected in cigarette smokers ${ }^{18}$.

Moreover, patient-related factors such as compliance and quality of home care are known to affect the clinical outcomes after periodontal therapy ${ }^{19}$. There is usually a dose-response effect between the number of cigarettes smoked and negative effects of smoking on various health problems including periodontal diseases. Clinical findings from a comparative study that compares non-smokers, current smokers and passive smokers, reported further support for a negative, dose-related effect of tobacco on periodontal health ${ }^{5}$. The authors concluded that the tendency for a more prevalent detection of $T$. denticola and for a suppressed inflammatory response observed in the smokers may at least partly explain the increased susceptibility to periodontal destruction. However, not all studies report the pack-years or other similar data for the smoker group. Another very important issue in studies focusing on the possible effects of smoking on periodontal health is whether or not the smoking status is chemically validated. Usually, researchers rely on self-reports of the study participants while assigning the patients into smoker or non-smoker groups. Yet, self-reports may not always reflect the reality on the status of smoking and, therefore, chemical validation is of utmost importance. Chemical validation can easily be performed by determining cotinine levels in saliva samples. Cotinine is a major component of tobacco smoke that has a long half-life and its concentration in biofluids such as saliva, urine, and blood provide reliable information on the state of smoking of an individual ${ }^{3,5}$. Smokers exhibit salivary cotinine levels above $100 \mathrm{ng} / \mathrm{mL}$, whereas passive smoking may be reflected by $5-7 \mathrm{ng} / \mathrm{mL}$ salivary cotinine concentrations ${ }^{20,21}$.

\section{Smoking and surgical periodontal treatment}

Surgical periodontal treatment can be applied after non-surgical periodontal treatment. This treatment includes wide variety of surgical procedures for the patient's need ${ }^{22}$. In this context, open flap debridement for patients with deep pockets, periodontal plastic surgery for individuals with gingival recession, periodontal regeneration surgery for individuals with bone defects, and implant surgery for patients with tooth deficiency can be performed ${ }^{22,23}$. Nonsurgical periodontal treatment of the patient must be completed prior to the surgical intervention, and gingival tissues must be inflammation free. Experience of the dentist, conditions of the surgery and home care, as well as habits of the patient, may affect the postoperative recovery ${ }^{22}$. The harmful effects of smoking, especially in the wound healing period after periodontal surgical treatment, have been mentioned previously ${ }^{24,25}$.

Periodontal access flap is generally applied to areas that cannot be reached during non-surgical periodontal treatment to remove subgingival deposits and do root planing with a clearer vision. Reductions in gingival inflammation and probing depth (PD) with gain in clinical attachment level (CAL) are expected to be achieved after this treatment ${ }^{24}$. Possible detrimental effects of smoking on the outcomes of flap surgery have been investigated in several studies ${ }^{6,26-30}$. Effects of cigarette smoking on the outcomes of surgical periodontal therapy (modified Widman flap) were analyzed in 54 patients ( 24 of them were smokers) with moderate to severe periodontitis and deep periodontal pockets ${ }^{26}$. The authors reported that smoking may impair the outcomes of surgical periodontal therapy. Ah et al. ${ }^{6}$ performed a similar study in 74 patients and observed less improvement in clinical periodontal parameters in smokers. In another study, effects of cigarette consumption on active periodontal treatment (non-surgical and surgical periodontal treatment) were evaluated and it was stated that heavy smokers (20 cigarettes/day) and light smokers (<19 cigarettes/day) exhibited less PD reduction and CAL gain than ex-smokers and never smokers ${ }^{27}$. Scabbia et al. ${ }^{28}$ and Trombelli et al. ${ }^{29}$ evaluated effects of smoking on the clinical outcomes of open flap debridement in deep pockets 
and furcation defects. Both studies indicated that less improvement was observed in smoker patients than non-smoker patients after treatment ${ }^{28,29}$. In another study, local immune response was found to be poorer in the smokers following different periodontal treatment modalities in chronic periodontitis patients $^{30}$. In a review paper, the authors concluded that smoking has negative effects on surgical periodontal treatment outcomes and this situation should be explained to smoker patients during the treatment planning phase ${ }^{25}$. However, other factors such as poorly controlled diabetes mellitus, stress, immunodeficiency, older age and female gender should not be underestimated, when considering the effects of smoking on periodontal surgery outcomes ${ }^{24}$.

Another step of periodontal surgery aims to correct mucogingival deformities. Gingival recessions, especially in the anterior region can cause esthetic problems and patients seek treatment also for the dental hypersensitivity that may occur on the root surfaces. Plastic periodontal surgical interventions for root coverage are very comprehensive and require delicate procedures with technical difficulties. Chambrone et al. ${ }^{31}$ stated that significant improvements can be achieved in gingival recessions and clinical attachment levels in both smokers and non-smokers, but the root coverage rate with subepithelial connective tissue graft was found to be lower in smokers. Silva et al. ${ }^{32}$ evaluated the effects of smoking on free gingival graft procedure in the treatment of gingival recessions and reported that blood supply was decreased, and epithelization was delayed in the donor sites of smoker patients. However, no detectable effects on postoperative dimensional changes of free gingival grafts were found ${ }^{32}$. Another study with similar scope and design reported that the free gingival graft exhibited more shrinkage in smokers than in non-smokers and failed to completely cover the recession area ${ }^{33}$. On the other hand, comparable clinical outcomes were found in smoker and non-smoker patients following coronally advanced flap for root coverage ${ }^{9}$. Accordingly, no difference was detected in complete root coverage rates between smoker and non-smoker patients who underwent coronally advanced flap procedure for root coverage $\mathrm{e}^{34}$. However, there is a dominance of evidence in the existing literature indicating that the rate of complete root coverage in smokers is lower than the rate in non-smokers ${ }^{35}$.

Regenerative periodontal surgical approach with various barrier membranes and bone graft materials has been widely used for treatment of intrabony defects during the last two decades to regenerate the lost periodontal tissues ${ }^{36}$. The findings of a retrospective study emphasized that smoking negatively affected the success of guided tissue regeneration procedures ${ }^{37}$. Similarly, another study evaluating treatment of Class II furcation defects using bioresorbable barrier membrane with and without decalcified freeze-dried bone allograft, reported negative effects of smoking ${ }^{38}$. On the contrary, the regenerative procedure involving supracrestal soft tissue preservation together with enamel matrix proteins (EMP), revealed no significant negative effect of smoking on CAL gain and probing depth reduction ${ }^{39}$. Loos et al. ${ }^{40}$ stated that smoking exhibited adverse effects on healing after regenerative periodontal surgery. In the meta-analysis of Patel et al. ${ }^{41}$, it was reported that smoking negatively affected regenerative periodontal treatment outcomes. In a review on regenerative periodontal treatment procedures in intrabony defects, smoking was stated as an important detrimental factor for the success of this treatment and should be considered while making the treatment plan $^{42}$.

Placing intrabony dental implants has become a common treatment modality in rehabilitation of dentition after single or multiple tooth $\operatorname{loss}^{23}$. Complications of dental implants are increasing with the increase in dental implant applications ${ }^{43}$. Smoking has been stated as an important risk factor deteriorating the prognosis of dental implants and, therefore, should be taken into account in treatment planning, and patients should be informed about the risks ${ }^{44}$. Reduced success rates of dental implants and increases in the extent and severity of marginal bone loss have been reported ${ }^{45,46}$. In a recent systematic review and meta-analysis published in 2020, the number of cigarettes smoked per day was reported to be inversely correlated with the implant success rate ${ }^{47}$. Based on the available evidence, it may be suggested that patients who currently smoke as well as those who are passive smokers should be warned about the possible complications of implant applications, and patients with 5-10 pack-years or more should not be regarded as candidates for implant placement, but rather treated by conventional prosthetic 
approaches ${ }^{48}$. In a recent review evaluating the possible effects of other tobacco products on dental implants, the harmful effects of nicotine-containing products on the peri-implant tissues were emphasized although there is limited scientific evidence ${ }^{49}$.

\section{Smoking and supportive periodontal treatment}

Supportive periodontal therapy aims to maintain periodontal health achieved by active periodontal therapy either with non-surgical or surgical modalities ${ }^{50}$. Following resolution of clinical signs and symptoms of periodontal disease by active periodontal treatment, patients' motivation tends to decrease over time, and many patients may not continue performing oral care adequately. For this reason, supportive periodontal treatment needs to be planned considering the present risk factors that may cause recurrence of the disease, and periodontal condition of the patient should be monitored with regular recalls; motivation and instructions for adequate oral care should be provided repeatedly. Smoking is among the risk factors that negatively affect periodontal supportive treatment outcomes ${ }^{51}$. The clinical and biochemical parameters of patients, who received supportive periodontal treatment with regular recall visits after surgical periodontal treatment were evaluated for five years and significantly greater alveolar bone loss together with higher tumor necrosis factor-alpha levels were found in smoker patients ${ }^{7}$. Evaluation of the effects of smoking over 20 years revealed greater marginal bone resorption and tooth loss in smokers $^{52}$. Another study indicated that smoking was directly related to tooth $\operatorname{loss}^{53}$. Similarly, Matuliene et al. ${ }^{54}$ stated that the number of residual pockets and tooth loss increased with the increase in the number of cigarettes smoked per day. Quitting smoking may reduce the risk of tooth loss over time ${ }^{55}$. However, this risk of tooth loss becomes equal to that in neversmoker patients only after smoking abstinence for 9-12 years, and this information may be used to encourage smoker patients to quit smoking along with periodontal treatment ${ }^{55}$.

Pretzl et al ${ }^{56}$ followed periodontally compromised patients for 20 years after completion of active periodontal therapy and emphasized smoking as a major reason for the increase in tooth loss rates, and for non-compliance to supportive periodontal therapy together with older age and confounding systemic diseases such as diabetes. These risk factors were further verified to increase the risk of tooth $\operatorname{loss}^{57}$.

Supportive periodontal treatment plays a critical role in maintaining the periodontal health status of the patient after active periodontal therapy ${ }^{51}$. Patient's age, habits, lifestyle, and systemic condition should be followed carefully during the supportive periodontal treatment. Frequency of recall visits should be planned on each patient's individual characteristics and needs ${ }^{58}$.

\section{Future considerations}

Future large-scale follow-up studies that comparatively evaluate current smokers, ex-smokers, never smokers, and also passive smokers, whose smoking status is chemically validated, may help to better clarify the possible relationship between smoking and periodontal treatment outcomes. Moreover, studies that stick to some basic standards with regard to clinical periodontal measurement and periodontal treatment methods are warranted. Another expectation from future studies is focusing not only on conventional cigarettes but also waterpipes and e-cigarettes, as their usage rates are increasing particularly among young people.

\section{CONCLUSION}

The existing literature clearly suggests that smoking has adverse effects on the periodontal treatment outcomes. Therefore, smoker patients should be informed about these detrimental effects, and advice and counselling on quitting smoking should be considered by the dental-care provider along with the active and supportive periodontal treatment phases.

\section{REFERENCES}

1. Loos BG, Needleman I. Endpoints of active periodontal therapy. J Clin Periodontol. 2020;47(Suppl 22):61-71. doi:10.1111/jcpe.13253

2. Papapanou PN, Sanz M, Buduneli N, et al. Periodontitis: Consensus report of workgroup 2 of the 2017 World Workshop on the Classification of Periodontal and PeriImplant Diseases and Conditions. J Periodontol. 2018;89 Suppl 1:S173-S182. doi:10.1002/JPER.17-0721

3. Montero E, La Rosa M, Montanya E, et al. Validation of self-reported measures of periodontitis in a Spanish Population. J Periodontal Res. 2020;55(3):400-409. doi:10.1111/jre.12724

4. Vouros ID, Kalpidis CD, Chadjipantelis T, Konstantinidis AB. Cigarette smoking associated with advanced 
periodontal destruction in a Greek sample population of patients with periodontal disease. J Int Acad Periodontol. 2009;11(4):250-257. Accessed May 30, 2021. https:// pubmed.ncbi.nlm.nih.gov/19886400/

5. Kanmaz B, Lamont G, Danacı G, Gogeneni H, Buduneli $\mathrm{N}$, Scott DA. Microbiological and biochemical findings in relation to clinical periodontal status in active smokers, non-smokers and passive smokers. Tob Induc Dis. 2019;17(March). doi:10.18332/tid/104492

6. Ah MK, Johnson GK, Kaldahl WB, Patil KD, Kalkwarf KL. The effect of smoking on the response to periodontal therapy. J Clin Periodontol. 1994;21(2):91-97. doi:10.1111/j.1600-051x.1994.tb00285.x

7. Boström L, Linder LE, Bergström J. Influence of smoking on the outcome of periodontal surgery. A 5-year follow-up. J Clin Periodontol. 1998;25(3):194-201. doi:10.1111/j.1600-051x.1998.tb02428.x

8. D'Aiuto F, Ready D, Parkar M, Tonetti MS. Relative contribution of patient-, tooth-, and site-associated variability on the clinical outcomes of subgingival debridement. I. Probing depths. J Periodontol. 2005;76(3):398-405. doi:10.1902/jop.2005.76.3.398

9. Kaval B, Renaud DE, Scott DA, Buduneli N. The role of smoking and gingival crevicular fluid markers on coronally advanced flap outcomes. J Periodontol. 2014;85(3):395-405. doi:10.1902/jop.2013.120685

10. Preshaw PM, Holliday R, Law H, Heasman PA. Outcomes of non-surgical periodontal treatment by dental hygienists in training: impact of site- and patient-level factors. Int J Dent Hyg. 2013;11(4):273-279. doi:10.1111/idh.12032

11. van der Weijden GA, de Slegte C, Timmerman MF, van der Velden U. Periodontitis in smokers and non-smokers: intra-oral distribution of pockets. J Clin Periodontol. 2001;28(10):955-960. doi:10.1034/j.1600-051x.2001.028010955.x

12. Ardais R, Mário Tde G, Boligon J, Kantorski KZ, Moreira CH. The effect of smoking on bleeding on probing after nonsurgical periodontal therapy: a quasi-experimental study. Braz Oral Res. 2014;28:1-7. doi:10.1590/1807-3107bor-2014.vol28.0058

13. Eltas A, Orbak R. Clinical effects of Nd:YAG laser applications during nonsurgical periodontal treatment in smoking and nonsmoking patients with chronic periodontitis. Photomed Laser Surg. 2012;30(7):360-366. doi:10.1089/pho.2011.3184

14. Jin L, Wong KY, Leung WK, Corbet EF. Comparison of treatment response patterns following scaling and root planing in smokers and non-smokers with untreated adult periodontitis. J Clin Dent. 2000;11(2):35-41. Accessed May 30, 2021. https://pubmed.ncbi.nlm.nih. gov/11460281/

15. Türkoğlu O, Eren G, Emingil G, Azarsız E, Kutukculer N, Atilla G. Does smoking affect gingival crevicular fluid LL37 levels following non-surgical periodontal treatment in chronic periodontitis? Arch Oral Biol. 2016;61:98-105. doi:10.1016/j.archoralbio.2015.10.018

16. Kanmaz B, Lappin DF, Nile CJ, Buduneli N. Effects of smoking on non-surgical periodontal therapy in patients with periodontitis Stage III or IV, and Grade C. J Periodontol. 2020;91(4):442-453. doi:10.1002/JPER.19-0141

17. AlAhmari F, Ahmed HB, Al-Kheraif AA, Javed F, Akram Z. Effectiveness of scaling and root planning with and without adjunct antimicrobial photodynamic therapy in the treatment of chronic periodontitis among cigarettesmokers and never-smokers: A randomized controlled clinical trial. Photodiagnosis Photodyn Ther. 2019;25:247252. doi:10.1016/j.pdpdt.2019.01.006

18. ALHarthi SS, BinShabaib M, Akram Z, Rahman I, Romanos GE, Javed F. Impact of cigarette smoking and vaping on the outcome of full-mouth ultrasonic scaling among patients with gingival inflammation: a prospective study. Clin Oral Investig. 2019;23(6):2751-2758. doi:10.1007/s00784-018-2725-2

19. Kwok V, Caton JG. Commentary: prognosis revisited: a system for assigning periodontal prognosis. J Periodontol. 2007;78(11):2063-2071. doi:10.1902/jop.2007.070210

20. Yamamoto Y, Nishida N, Tanaka M, et al. Association between passive and active smoking evaluated by salivary cotinine and periodontitis. J Clin Periodontol. 2005;32(10):10411046. doi:10.1111/j.1600-051X.2005.00819.x

21. Etzel RA. A review of the use of saliva cotinine as a marker of tobacco smoke exposure. Prev Med. 1990;19(2):190197. doi:10.1016/0091-7435(90)90020-k

22. Graziani F, Karapetsa D, Alonso B, Herrera D. Nonsurgical and surgical treatment of periodontitis: how many options for one disease? Periodontol 2000. 2017;75(1):152-188. doi:10.1111/prd.12201

23. Hong DGK, Oh JH. Recent advances in dental implants. Maxillofac Plast Reconstr Surg. 2017;39(1):33. doi:10.1186/s40902-017-0132-2

24. Javed F, Al-Rasheed A, Almas K, Romanos GE, Al-Hezaimi K. Effect of cigarette smoking on the clinical outcomes of periodontal surgical procedures. Am J Med Sci. 2012;343(1):78-84. doi:10.1097/MAJ.0b013e318228283b

25. Kotsakis GA, Javed F, Hinrichs JE, Karoussis IK, Romanos GE. Impact of cigarette smoking on clinical outcomes of periodontal flap surgical procedures: a systematic review and meta-analysis. J Periodontol. 2015;86(2):254-263. doi:10.1902/jop.2014.140452

26. Preber H, Bergström J. Effect of cigarette smoking on periodontal healing following surgical therapy. J Clin Periodontol. 1990;17(5):324-328. doi:10.1111/j.1600-051x.1990.tb01098.x

27. Kaldahl WB, Johnson GK, Patil KD, Kalkwarf KL. Levels of cigarette consumption and response to periodontal therapy. J Periodontol. 1996;67(7):675-681. doi:10.1902/jop.1996.67.7.675

28. Scabbia A, Cho KS, Sigurdsson TJ, Kim CK, Trombelli L. Cigarette smoking negatively affects healing response following flap debridement surgery. J Periodontol. 
2001;72(1):43-49. doi:10.1902/jop.2001.72.1.43

29. Trombelli L, Cho KS, Kim CK, Scapoli C, Scabbia A. Impaired healing response of periodontal furcation defects following flap debridement surgery in smokers. A controlled clinical trial. J Clin Periodontol. 2003;30(1):8187. doi:10.1034/j.1600-051x.2003.10182.x

30. Orbak R, Erciyas K, Kaya H. Flow-cytometric analysis of T-lymphocyte subsets after different treatment methods in smokers and non-smokers with chronic periodontitis. Int Dent J. 2003;53(3):159-164. doi:10.1111/j.1875-595x.2003.tb00741.x

31. Chambrone L, Chambrone D, Pustiglioni FE, Chambrone LA, Lima LA. The influence of tobacco smoking on the outcomes achieved by root-coverage procedures: a systematic review. J Am Dent Assoc. 2009;140(3):294306. doi:10.14219/jada.archive.2009.0158

32. Silva CO, Ribeiro Edel P, Sallum AW, Tatakis DN. Free gingival grafts: graft shrinkage and donor-site healing in smokers and non-smokers. J Periodontol. 2010;81(5):692-701. doi:10.1902/jop.2010.090381

33. Tawfik Diab AY, El-Destawy MT, Mandour HM. Efficacy of free gingival graft in treatment of localized gingival recession in smokers and non-smokers: Donor site healing, graft shrinkage and success. AlAzhar Journal of Dental Science. 2020;23(4):401-407. doi:10.21608/ajdsm.2020.26633.1047

34. Zucchelli G, Tavelli L, Ravidà A, Stefanini M, SuárezLópez Del Amo F, Wang HL. Influence of tooth location on coronally advanced flap procedures for root coverage. J Periodontol. 2018;89(12):1428-1441. doi:10.1002/JPER.18-0201

35. Yadav AP, Kulloli A, Shetty S, Ligade SS, Martande SS, Gholkar MJ. Sub-epithelial connective tissue graft for the management of Miller's class I and class II isolated gingival recession defect: A systematic review of the factors influencing the outcome. J Investig Clin Dent. 2018;9(3):e12325. doi:10.1111/jicd.12325

36. Cortellini P, Tonetti MS. Clinical concepts for regenerative therapy in intrabony defects. Periodontol 2000. 2015;68(1):282-307. doi:10.1111/prd.12048

37. Trombelli L, Kim CK, Zimmerman GJ, Wikesjö UM. Retrospective analysis of factors related to clinical outcome of guided tissue regeneration procedures in intrabony defects. J Clin Periodontol. 1997;24(6):366371. doi:10.1111/j.1600-051x.1997.tb00199.x

38. Luepke PG, Mellonig JT, Brunsvold MA. A clinical evaluation of a bioresorbable barrier with and without decalcified freeze-dried bone allograft in the treatment of molar furcations. J Clin Periodontol. 1997;24(6):440-446. doi:10.1111/j.1600-051x.1997.tb00209.x

39. Trombelli L, Bottega S, Zucchelli G. Supracrestal soft tissue preservation with enamel matrix proteins in treatment of deep intrabony defects. J Clin Periodontol. 2002;29(5):433-439. doi:10.1034/j.1600-051x.2002.290508.x
40. Loos BG, Louwerse PH, Van Winkelhoff AJ, et al. Use of barrier membranes and systemic antibiotics in the treatment of intraosseous defects. J Clin Periodontol. 2002;29(10):910921. doi:10.1034/j.1600-051x.2002.291006.x

41. Patel RA, Wilson RF, Palmer RM. The effect of smoking on periodontal bone regeneration: a systematic review and meta-analysis. J Periodontol. 2012;83(2):143-155. doi:10.1902/jop.2011.110130

42. Reynolds MA, Kao RT, Camargo PM, et al. Periodontal regeneration - intrabony defects: a consensus report from the AAP Regeneration Workshop. J Periodontol. 2015;86(2 Suppl):S105-S107. doi:10.1902/jop.2015.140378

43. Liaw K, Delfini RH, Abrahams JJ. Dental Implant Complications. Semin Ultrasound CT MR. 2015;36(5):427-433. doi:10.1053/j.sult.2015.09.007

44. Strietzel FP, Reichart PA, Kale A, Kulkarni M, Wegner B, Küchler I. Smoking interferes with the prognosis of dental implant treatment: a systematic review and meta-analysis. J Clin Periodontol. 2007;34(6):523-544. doi:10.1111/j.1600-051X.2007.01083.x

45. Bahrami G, Vaeth M, Kirkevang LL, Wenzel A, Isidor F. The impact of smoking on marginal bone loss in a 10-year prospective longitudinal study. Community Dent Oral Epidemiol. 2017;45(1):59-65. doi:10.1111/cdoe.12260

46. Nazeer J, Singh R, Suri P, et al. Evaluation of marginal bone loss around dental implants in cigarette smokers and nonsmokers. A comparative study. J Family Med Prim Care. 2020;9(2):729-734. doi:10.4103/jfmpc.jfmpc_1023_19

47. Naseri R, Yaghini J, Feizi A. Levels of smoking and dental implants failure: A systematic review and metaanalysis. J Clin Periodontol. 2020;47(4):518-528. doi:10.1111/jcpe.13257

48. Twito D, Sade P. The effect of cigarette smoking habits on the outcome of dental implant treatment. PeerJ. 2014;2:e546. doi:10.7717/peerj.546

49. Javed F, Rahman I, Romanos GE. Tobacco-product usage as a risk factor for dental implants. Periodontol 2000. 2019;81(1):48-56. doi:10.1111/prd.12282

50 . Lindhe J, Nyman S. The effect of plaque control and surgical pocket elimination on the establishment and maintenance of periodontal health. A longitudinal study of periodontal therapy in cases of advanced disease. J Clin Periodontol. 1975;2(2):67-79. doi:10.1111/j.1600-051x.1975.tb01727.x

51. Tan AE. Periodontal maintenance. Aust Dent J. 2009;54(s1):S110-S117. doi:10.1111/j.1834-7819.2009.01149.x

52. Jansson L, Lavstedt S. Influence of smoking on marginal bone loss and tooth loss--a prospective study over 20 years. J Clin Periodontol. 2002;29(8):750-756. doi:10.1034/j.1600-051x.2002.290812.x

53. Hanioka T, Ojima M, Tanaka K, Aoyama H. Relationship between smoking status and tooth loss: findings from national databases in Japan. J Epidemiol. 2007;17(4):125132. doi:10.2188/jea.17.125

54. Matuliene G, Pjetursson BE, Salvi GE, et al. Influence of residual pockets on progression of 
periodontitis and tooth loss: results after 11 years of maintenance. J Clin Periodontol. 2008;35(8):685-695. doi:10.1111/j.1600-051X.2008.01245.x

55. Krall EA, Dietrich T, Nunn ME, Garcia RI. Risk of tooth loss after cigarette smoking cessation. Prev Chronic Dis. 2006;3(4). Accessed May 30, 2021. http://www.cdc.gov/ pcd/issues/2006/oct/05_0243.htm

56. Pretzl B, El Sayed S, Weber D, Eickholz P, Bäumer A. Tooth loss in periodontally compromised patients: Results 20 years after active periodontal therapy. J Clin Periodontol. 2018;45(11):1356-1364. doi:10.1111/jcpe. 13010

57. Helal O, Göstemeyer G, Krois J, et al. Predictors for tooth loss in periodontitis patients: Systematic review and meta-analysis. J Clin Periodontol. 2019;46(7):699-712. doi:10.1111/jcpe.13118

58. Trombelli L, Simonelli A, Franceschetti G, Maietti E, Farina R. What periodontal recall interval is supported by evidence? Periodontol 2000. 2020;84(1):124-133. doi:10.1111/prd.12340
CONFLICTS OF INTEREST

The authors have completed and submitted the ICMJE Form for Disclosure of Potential Conflicts of Interest and none was reported.

\section{FUNDING}

There was no source of funding for this study.

ETHICAL APPROVAL AND INFORMED CONSENT

Ethical approval and informed consent were not required as this is a review of existing literature.

\section{DATA AVAILABILITY}

The data supporting this study are available from the authors on reasonable request.

\section{AUTHORS' CONTRIBUTIONS}

NB provided primary oversight to the organization of the review, as well as specific sections on periodontal treatment. MK and BK provided the content for the review.

PROVENANCE AND PEER REVIEW

Not commissioned; externally peer reviewed. 